\title{
Self-generated visual imagery alters the mere exposure effect
}

\author{
CATHERINE CRAVER-LEMLEY \\ Elizabethtown College, Elizabethtown, Pennsylvania \\ and \\ ROBERT F. BORNSTEIN \\ Adelphi University, Garden City, New York
}

\begin{abstract}
To determine whether self-generated visual imagery alters liking ratings of merely exposed stimuli, 79 college students were repeatedly exposed to the ambiguous duck-rabbit figure. Half the participants were told to picture the image as a duck and half to picture it as a rabbit. When participants made liking ratings of both disambiguated versions of the figure, they rated the version consistent with earlier encoding more positively than the alternate version. Implications of these findings for theoretical models of the exposure effect are discussed.
\end{abstract}

During the past 35 years, there have been more than 250 published experiments assessing aspects of Zajonc's (1968) mere exposure effect, according to which repeated, unreinforced exposure to a stimulus is sufficient to enhance one's attitude toward that stimulus (Bornstein, 1989; Bornstein \& Craver-Lemley, 2004). A broad array of stimuli-including photographs, drawings, matrices, polygons, real words, nonsense words, ideographs, musical selections, and people encountered in and out of the laboratory produce robust mere exposure effects. The exposure effect occurs under a wide variety of conditions, including situations wherein participants' awareness of stimulus content is obviated by subliminal stimulus exposures or concurrent performance of resource-intensive tasks (Bargh, 2001; Bornstein, 1992; Kunst-Wilson \& Zajonc, 1980; Murphy \& Zajonc, 1993).

Although the existence of the exposure effect is uncontroversial, researchers disagree on the processes that underlie the effect. Zajonc $(1980,2001)$ argued that mere exposure effects represent pure affective responses that occur with minimal intervening cognitive activity (see also Murphy, Monahan, \& Zajonc, 1995). The existence of exposure effects in primates and other mammals (see, e.g., Hill, 1978) supports Zajonc's affective primacy hypothesis, as do data demonstrating that affective "spillover" effects alter judgments of related-and even unrelatedstimuli in mere exposure experiments (Monahan, Murphy,

Portions of these findings were presented at the 2006 meeting of the Association for Psychological Science in New York. We thank Danielle Alexander for her help with programming and analysis and Cassidy Zammit for collecting the data for this study. Correspondence regarding this article should be sent to C. Craver-Lemley, Department of Psychology, Elizabethtown College, One Alpha Drive, Elizabethtown, PA 17022 or R. F. Bornstein, Derner Institute of Advanced Psychological Studies, 212F Blodgett Hall, Adelphi University, Garden City, NY 11530 (e-mail: lemleyce@etown.edu or bornstein@adelphi.edu).
\& Zajonc, 2000). Winkielman and Cacioppo's (2001) finding that exposure-induced ease of processing alters zygomaticus major muscle activity further suggests that hedonic fluency plays a role in the exposure effect, and may help account for affective responding without extensive cognitive processing (for related findings, see also Harmon-Jones \& Allen, 2001; Zárate, Sanders, \& Garza, 2000).

An alternative perspective on the exposure effect is derived from the work of Seamon, Brody, and Kauff (1983), Mandler, Nakamura, and Van Zandt (1987), and others (e.g., Bornstein \& D'Agostino, 1994; Klinger \& Greenwald, 1994; A. Y. Lee, 2001), who demonstrated that under certain conditions higher level cognitive processes moderate liking judgments of merely exposed stimuli. The results of these experiments, taken together, have been used to bolster an explanation of the exposure effect, which contends that affective reactions to merely exposed stimuli sometimes entail more extensive cognitive processing of stimulus content beyond rudimentary encoding of stimulus properties.

Several lines of evidence support the notion that complex cognitive processes are involved in at least some variations of the mere exposure effect. For example, Bonanno and Stillings (1986) found that repeated exposure to random polygons influenced not only physical judgments of polygon properties (e.g., brightness and darkness), but also affect judgments. These results suggest that repeated exposure results in the formation of a mental representation of each familiarized stimulus, with subsequent exposures during the test phase leading to activation of these representations. Parallel findings with more socially relevant stimuli were obtained by M. A. Lee, Sundberg, and Bernstein (1993), who found that repeated viewing of photographs of college-age men influenced height estimates as well as affect judgments regarding the individuals pictured in the photographs.

Along somewhat different lines, Seamon and his colleagues found that recognition memory, but not affective 
responding, was impaired by reflection and size transformations of three-dimensional drawings (Seamon et al., 1997; Seamon, McKenna, \& Binder, 1998) and objects (Seamon \& Delgado, 1999) between exposure and test. On the basis of these findings, Seamon and his colleagues suggested that exposure effects represent a form of implicit memory based in part on encoding of structural descriptions of merely exposed stimuli.

These results, as well as those of other recent mere exposure experiments (e.g., Compton, Williamson, Murphy, \& Heller, 2002; Rhodes, Halberstadt, \& Brajkovich, 2001) suggest that, under conditions where enough cognitive resources are available to process stimuli extensively, exposure effects reflect encoding during exposure and subsequent retrieval at test of mental images of merely exposed stimuli. If this is so, asking participants to deliberately alter mental images of merely exposed stimuli during familiarization should influence the exposure effect in predictable ways, but no studies have explored this possibility empirically.

The present experiment was based in part on the methods and findings of Chambers and Reisberg (1985), who asked participants to memorize the ambiguous duck-rabbit figure, generate a mental image, then reinterpret the self-generated image. Most participants were unable to do this successfully. Because people find this reinterpretation task relatively easy when the figure is perceived, not imagined, Chambers and Reisberg concluded that mental images are more resistant to cognitive transformation than are actual perceived images.

Thus, Chambers and Reisberg's (1985) paradigm can potentially provide strong evidence for the role of mental imagery in the mere exposure effect. Specifically, when participants are repeatedly exposed to the ambiguous duckrabbit figure and instructed to encode one interpretation of the figure consistently throughout exposures, they should show a strong exposure effect for the disambiguated figure at test only when the figure matches their mental images. When the opposite version of the disambiguated figure is shown at test, the exposure effect should not occur.

\section{METHOD}

\section{Participants}

Seventy-nine undergraduates (68 women and $11 \mathrm{men}$ ) received course credit for taking part in the study. All participants had normal or corrected-to-normal vision. The experimenters were undergraduate research assistants unaware of the expected outcome.

An additional 47 participants provided pilot ratings of both disambiguated versions of the duck-rabbit stimulus to ascertain whether the duck and rabbit versions of the stimulus were equally likable prior to stimulus exposures. No pilot participants took part in the experiment proper.

\section{Materials}

Stimuli were displayed on a computer monitor set at eye level approximately $2 \mathrm{ft}$ from each participant. Stimuli were centered on the screen. Stimuli presented during the exposure phase of the study consisted of an ambiguous figure $\left(13^{1 / 2} \times 9^{1 / 2} \mathrm{~cm}\right)$ that could be interpreted either as a rabbit or as a duck (see Figure 1A), and a geometric form from the Barron-Welsh Art Scale (Bornstein \& D'Agostino, 1994).

During the test phase of the experiment, participants viewed two disambiguated versions of the duck-rabbit figure, each $13 \frac{1}{2} \times$ $91 / 2 \mathrm{~cm}$ (see Figures $1 \mathrm{~B}$ and 1C). The ambiguous and disambiguated figures were similar to those used by Gopnik and Rosati (2001). A 9-point rating scale anchored with the terms dislike very much (1 point) and like very much (9 points) was used to obtain ratings of the stimuli.

\section{Procedure}

Participants were informed that they would be viewing pictures on the computer screen and that their task would be to rate those pictures at the end of the exposure period. Participants were individually tested in one of two conditions: In the rabbit condition, the participants $(n=$ 39 ) were told that the ambiguous picture viewed during the exposure phase was a picture of a rabbit; in the duck condition, participants $(n=$ 40) were told that the ambiguous picture was a duck. Participants in both groups actually viewed the same ambiguous figure (Figure 1A).

The format of each trial was as follows: A centered fixation dot was presented for $5 \mathrm{sec}$, followed by the word READY for $3 \mathrm{sec}$, after which either the ambiguous figure or the geometric figure appeared for 4 sec. Participants viewed 10 exposures of the ambiguous figure and 5 exposures of the geometric form, for a total of 15 exposure trials; stimuli were presented in a randomized (heterogeneous) sequence. For each trial, the participants were instructed to verbally identify which stimulus had been presented.

Upon completion of the exposure trials, participants were informed that two pictures would be presented on the computer screen and that they were to provide a liking rating for each picture. The disambiguated pictures were presented one at a time for 4 sec each, with viewing order randomized across participants. The procedure lasted approximately $10 \mathrm{~min}$.

\section{Pilot Ratings of Disambiguated Figures}

Pilot ratings were collected using the same 9-point dislike-like scale as was used in the experiment proper. To collect these ratings, both disambiguated versions of the duck-rabbit figure were printed on a single page, with a 9-point dislike-like scale immediately below each image. Counterbalancing the image order ensured that for half the pilot participants the duck version of the figure was rated first, and for the remaining half the rabbit version was rated first.

\section{RESULTS}

The mean liking rating of the duck version of the figure by pilot participants was $5.09(S D=1.43)$, whereas the

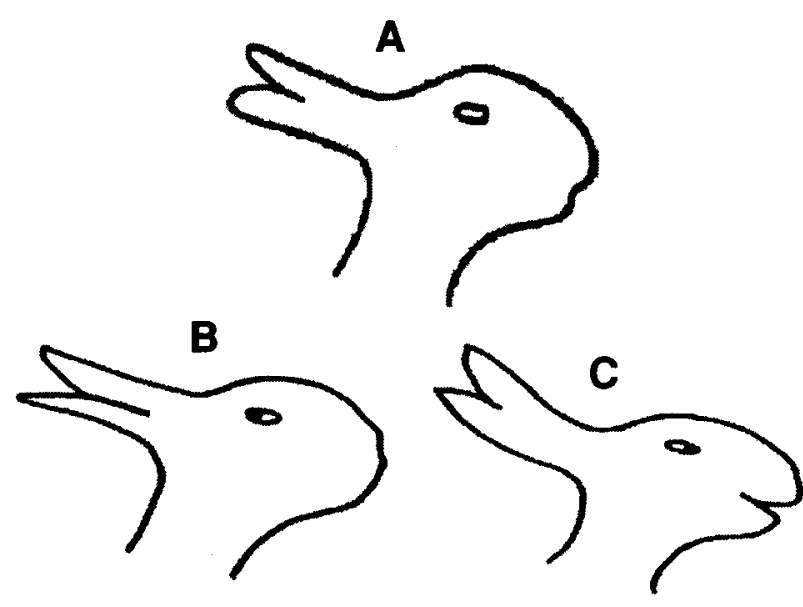

Figure 1. Three versions of the duck-rabbit figure. Figure 1A shows the typical (ambiguous) version of this figure; Figures 1B and $1 \mathrm{C}$ show the "disambiguated duck" and "disambiguated rabbit" versions of the figure. 
mean liking rating of the rabbit version was $5.11(S D=$ 1.69). These means did not differ $[t(46)=0.06, p=.95]$, confirming that prior to stimulus exposures the two disambiguated versions of the figure were equally likable.

The results of this experiment are summarized in Figure 2 . A 2 (encoding condition) $\times 2$ (disambiguated version of figure at test) mixed ANOVA revealed a significant interaction between encoding condition and figure version on liking ratings $[F(1,77)=24.94, p<.001]$. Participants who initially encoded the figure as a rabbit provided higher ratings of the disambiguated rabbit version of the figure $(M=6.21, S D=1.93)$ than of the disambiguated duck version of the figure $(M=5.32, S D=2.09)$. The opposite pattern was obtained for participants who initially encoded the figure as a duck: These participants' ratings of the rabbit and duck versions of the figure were $4.56(S D=2.23)$ and $6.10(S D=1.78)$, respectively.

Follow-up analyses comparing liking ratings of familiarized stimuli with baseline liking ratings revealed that, as expected, participants who initially encoded the image as a duck provided liking ratings of the duck version of the figure that were higher than baseline (no exposure) ratings of the disambiguated duck $[t(85)=2.96, p=.004]$. Similarly, participants who initially encoded the image as a rabbit provided ratings of the rabbit version of the figure that were higher than baseline (no exposure) ratings of the disambiguated rabbit $[t(84)=2.82, p=.006] .^{1}$

\section{DISCUSSION}

These results confirm that altering mental images of merely exposed stimuli affects subsequent liking ratings of those stimuli. These findings indicate that at least under certain conditions, mental images may moderate the mere exposure effect. Moreover, these results provide a potential explanation for the persistence of mere exposure effects over extended periods following stimulus exposure (see Bornstein, 1989; Seamon et al., 1983). If participants encode mental images of merely exposed stimuli during familiarization, long-term changes in affective responses to these stimuli may depend on retrieval of these previously encoded mental images days - or even weeks-after stimulus exposures. ${ }^{2}$

Although the predicted encoding condition $\times$ figure version interaction obtained in this experiment $(F=$ 24.94) represents a large effect size $(d=1.13$; see Cohen, 1990), the generalizability of this effect to other ambiguous stimuli remains open to question. Future studies should ascertain whether similar encoding manipulations alter affect ratings of other ambiguous figures (e.g., the "Sara Nader" saxophonist-woman's profile image) to document the robustness of this phenomenon across stimuli.

A skeptic might argue that because participants in this experiment were instructed to encode stimuli in a particular way, these results do not reflect "mere" exposure. In fact, several previous mere exposure experiments involved instructional and labeling manipulations designed to prompt participants to perceive and encode merely exposed stimuli in a particular manner (e.g., Perlman \& Oskamp, 1971; Wang \& Chang, 2004; Zajonc, Markus, \& Wilson, 1974). Moreover, Zajonc's original (1968) use of the term mere did not refer to the absence of an instructional set, but to the absence of reinforcement associated with stimulus exposures (see also Bargh, 2001; Bornstein

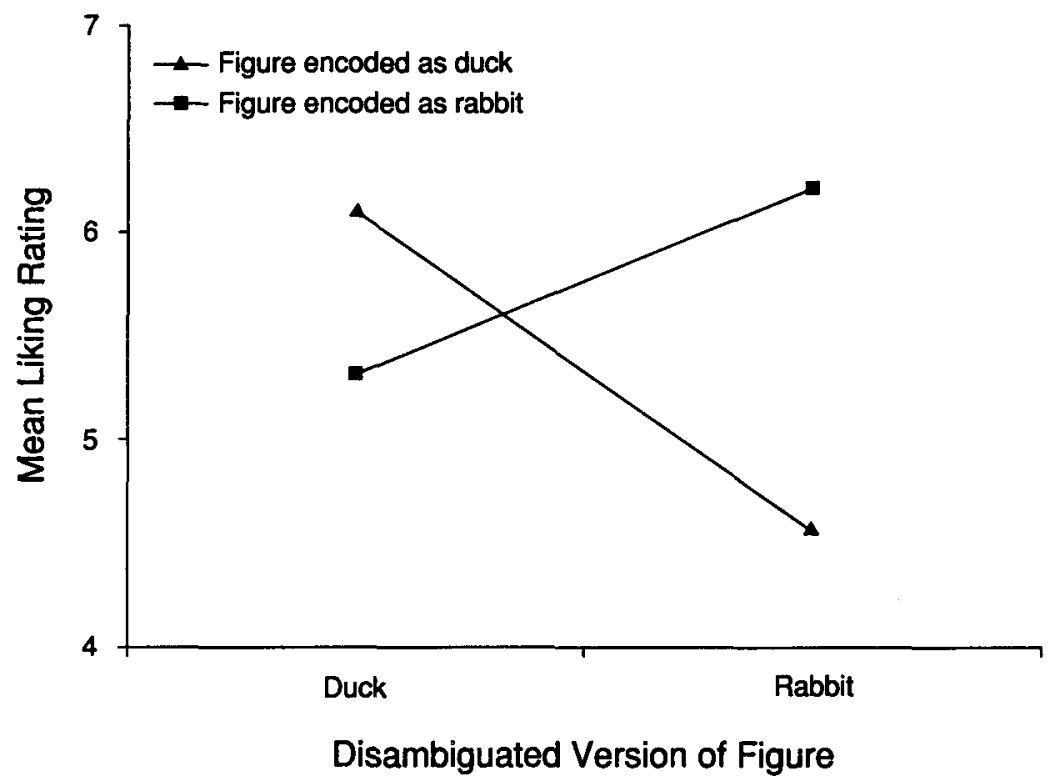

Figure 2. Liking ratings of disambiguated versions of the duck-rabbit figure as a function of encoding condition. Participants in the duck condition encoded the image as a duck during stimulus exposures; those in the rabbit condition encoded the image as a rabbit. 
\& Craver-Lemley, 2004). Because participants in the present investigation were not reinforced in any way during or after exposure to the critical stimuli, these results clearly represent a demonstration of the mere exposure effect.

Even though these results confirm that mental images of merely exposed stimuli moderate the exposure effect, they do not indicate that mental images invariably mediate the effect. Several studies have shown that under some conditions mere exposure effects show features of rapid, automatic, affect-driven responding (e.g., Winkielman \& Cacioppo, 2001), and in these situations higher level cognitive processes (including elaboration and categorization of mental images of merely exposed stimuli) may not play a role (see Zajonc, 2001). Moreover, it is not clear that mental images, self-generated or otherwise, are involved in exposure effects for stimuli other than photographs and drawings, such as foreign words and letter strings. In fact, evidence suggests that different psychological and neurological processes may underlie the exposure effect for visual and lexical stimuli (Compton et al., 2002; Zárate et al., 2000).

Thus, rather than resolving the affect-cognition debate, the present results - along with those of Compton et al. (2002) and others (e.g., M. A. Lee et al., 1993)-illustrate the complexity of this question and the importance of framing this issue not in terms of whether cognitive processes are involved in the exposure effect, but around the question of what cognitive and affective processes occur during stimulus exposures and affect ratings. The present results confirm that, at least under some circumstances, generation and conceptual categorization of an exposurederived mental image may play a role in the mere exposure effect. Whether this pattern supports the affective primacy hypothesis or the critical-importance-of-cognition perspective is less important than the fact that it points to a heretofore unstudied moderating variable - mental images of merely exposed stimuli-that may help researchers understand the exposure effect more completely.

\section{REFERENCES}

BARGH, J. A. (2001). The psychology of the mere. In J. A. Bargh \& D. K. Apsley (Eds.), Unraveling the complexities of social life: A festschrift in honor of Robert B. Zajonc (pp. 25-37). Washington, DC: American Psychological Association.

Bonanno, G. A., \& Stillings, N. A. (1986). Preference, familiarity, and recognition after repeated brief exposures to random geometric shapes. American Journal of Psychology, 99, 403-415.

BORNSTEIN, R. F. (1989). Exposure and affect: Overview and meta-analysis of research, 1968-1987. Psychological Bulletin, 106, 265-289.

BoRNSTEIN, R. F. (1992). Subliminal mere exposure effects. In R. F. Bornstein \& T. S. Pittman (Eds.), Perception without awareness: Cognitive, clinical, and social perspectives (pp. 191-210). New York: Guilford.

Bornstein, R. F., \& CRaver-LemLey, C. (2004). The mere exposure effect. In R. F. Pohl (Ed.), Cognitive illusions: $A$ handbook on fallacies and biases in thinking, judgement and memory (pp. 215-234). Hove, U.K.: Psychology Press.

Bornstein, R. F., \& D'Agostino, P. R. (1994). The attribution and discounting of perceptual fluency: Preliminary tests of a perceptual fluency/attributional model of the mere exposure effect. Social Cognition, 12, 103-128.

Chambers, D., \& Reisberg, D. (1985). Can mental images be ambigu- ous? Journal of Experimental Psychology: Human Perception \& Performance, 11, 317-328.

COHEN, J. (1990). Statistical power analysis for the behavional sciences (2nd ed.). Hillsdale, NJ: Erlbaum.

Compton, R. J., Williamson, S., MuRPhy, S. G., \& Heller, W. (2002). Hemispheric differences in affective response: Effects of mere exposure. Social Cognition, 20, 1-17.

GoPNIK, A., \& RosATI, A. (2001). Duck or rabbit? Reversing ambiguous figures and understanding ambiguous representations. Developmental Science, 4, 175-183.

Harmon-Jones, E., \& Allen, J. J. B. (2001). The role of affect in the mere exposure effect: Evidence from psychophysiological and individual differences approaches. Personality \& Social Psychology Bulletin, 27, 889-898.

HILL, W. F. (1978). Effects of mere exposure on preferences in nonhuman animals. Psychological Bulletin, 85, 1177-1198.

KLINGER, M. R., \& GreenWALD, A. G. (1994). Preferences need no inferences? The cognitive basis of unconscious mere exposure effects. In P. M. Niedenthal \& S. Kitayama (Eds.), The heart's eye: Emotional influences in perception and attention (pp. 67-85). Orlando: Academic Press.

KUNST-WILSON, W. R., \& ZAJONC, R. B. (1980). Affective discrimination of stimuli that cannot be recognized. Science, 207, 557-558.

LEE, A. Y. (2001). The mere exposure effect: An uncertainty reduction explanation revisited. Personality \& Social Psychology Bulletin, 27, $1255-1266$.

LeE, M. A., SundBerg, J. L., \& Bernstein, I. H. (1993). Concurrent processes: The affect-cognition relationship within the context of the "mere exposure" phenomenon. Perception \& Psychophysics, 54, 33-42.

MaNDleR, G., NAKamura, Y., \& VAN ZaNDT, B. J. (1987). Nonspecific effects of exposure on stimuli that cannot be recognized. Journal of Experimental Psychology: Learning, Memory, \& Cognition, 13, 646-648.

Monahan, J. L., MURPHY, S. T., \& ZaJonc, R. B. (2000). Subliminal mere exposure: Specific, general, and diffuse effects. Psychological Science, 11, 462-466.

MurPhy, S. T., Monahan, J. L., \& ZaJonc, R. B. (1995). Additivity of nonconscious affect: Combined effects of priming and exposure. Journal of Personality \& Social Psychology, 69, 589-602.

MURPHY, S. T., \& ZAJONC, R. B. (1993). Affect, cognition, and awareness: Priming with optimal and suboptimal stimulus exposures. Journal of Personality \& Social Psychology, 64, 723-739.

Perlman, D., \& OsKamp, S. (1971). The effects of picture content and exposure frequency on evaluations of Negroes and whites. Journal of Experimental Social Psychology, 7, 503-514.

PYLYSHYN, Z. W. (2002). Mental imagery: In search of a theory. Behavioral \& Brain Sciences, 25, 157-237.

Rhodes, G., HalberstadT, J., \& Brajkovich, G. (2001). Generalization of mere exposure effects to averaged composite faces. Social Cognition, 19, 57-70.

Seamon, J. G., Brody, N., \& KaUfF, D. M. (1983). Affective discrimination of stimuli that are not recognized: II. Effect of delay between study and test. Bulletin of the Psychonomic Society, 21, 187-189.

Seamon, J. G., \& Delgado, M. R. (1999). Recognition memory and affective preference for depth-rotated solid objects: Part-based structural descriptions may underlie the mere exposure effect. Visual Cognition, 6, 145-164.

Seamon, J. G., Ganor-Stern, D., Crowley, M. J., Wilson, S. M., WEBER, W. J., O'RourKe, C. M., \& MAHONEY, J. K. (1997). A mere exposure effect for transformed three-dimensional objects: Effects of reflection, size, or color changes on affect and recognition. Memory \& Cognition, 25, 367-374.

Seamon, J. G., McKenna, P. A., \& Binder, N. (1998). The mere exposure effect is differentially sensitive to different judgment tasks. Consciousness \& Cognition, 7, 85-102.

WANG, M. Y., \& Chang, H. C. (2004). The mere exposure effect and recognition memory. Cognition \& Emotion, 18, 1055-1078.

Winkielman, P., \& CACIOPPO, J. T. (2001). Mind at ease puts a smile on the face: Psychophysiological evidence that processing facilitation elicits positive affect. Journal of Personality \& Social Psychology, 81, 989-1000.

ZAJONC, R. B. (1968). Attitudinal effects of mere exposure. Journal of Personality \& Social Psychology Monographs, 9(2, Pt. 2), 1-27. 
ZAJONC, R. B. (1980). Feeling and thinking: Preferences need no inferences. American Psychologist, 31, 151-175.

ZAJONC, R. B. (2001). Mere exposure: A gateway to the subliminal. Current Directions in Psychological Science, 10, 224-228.

ZAJONC, R. B., MARKUS, H., \& WILSON, W. R. (1974). Exposure effects and associative learning. Journal of Experimental Social Psychology, 10, 248-263.

Zárate, M. A., Sanders, J. D., \& Garza, A. A. (2000). Neurological dissociations of social perception processes. Social Cognition, 18 , 223-251.

\section{NOTES}

1. Also as expected, liking ratings of the rabbit version of the figure from participants who initially encoded the image as a duck did not differ from baseline (no exposure) ratings of the disambiguated rabbit $[t(85)=$ $1.31, p=.19]$. Similarly, liking ratings of the duck version of the figure from participants who initially encoded the image as a rabbit did not differ from baseline ratings of the disambiguated duck $[t(84)=0.63$, $p=.53]$. In other words, liking ratings of the familiarized figure did not differ from baseline liking ratings when the figure was encoded in a manner inconsistent with that of the no-exposure figure.

2. These results are also consistent with those of Chambers and Reisberg (1985), and provide additional evidence that under certain conditions, mental images are less susceptible than actual percepts to deliberate reencoding and reinterpretation (see also Pylyshyn, 2002, for a discussion of this issue).

(Manuscript received October 7, 2005; revision accepted for publication April 21, 2006.) 